\title{
"Questionable" Behaviors and Practices in Academic Productivity in Postgraduate Studies in Mexico
}

\author{
Ana Esther Escalante-Ferrera, Luz Marina Ibarra Uribea, César Darío Fonseca Bautistab
}

\begin{abstract}
This paper reports the results acquired in a research work about "questionable" practices and behaviors in the academic production of researches and postgraduate social sciences and humanities studies of the programs that are appointed by the National Program of Quality Postgraduate Studies (PNPC, by its acronym in Spanish) in Mexico. Through a qualitative methodology, the authors interpreted some of the arguments that explain and/or justify certain practices in relation to doubled production, authorship, and coauthorship of academic products. In this paper, the authors present and analyze the results that they obtained after reviewing documents produced by professors and students of six postgraduate programs that are taught in two Mexican public universities. At the same time, the authors examine some of the practices that take place within said programs, given the institutional demands of improving finished studies efficiency. One of the hypotheses of this work is the demands that are imposed by external evaluations of academic processes on professors and their programs in order to reach desirable rates with the purpose of maintaining or increasing the levels of productivity, gives way to certain practices that must be analyzed. This work's theoretic framework is constituted by the contributions of career sociology and professional ethics.
\end{abstract}

\section{Keywords}

Ethics, "questionable" practices and behaviors, academic production, postgraduate studies

Through the continuous work that a group of researchers of public and private universities ${ }^{1}$ -including the authors of this paper, has developed throughout the last decade in relation with professional ethics in postgraduate studies in Mexico, the authors have gone into detail about the theoretic arguments regarding the values that are deemed important by students and university professors as well as the conducts associated to these values. In order to do so, the authors have taken professional ethics as a theoretic framework.

In this line of investigation, the authors tried to analyze the influence of postgraduate education programs, evaluation systems have over practices and behaviors that are manifested in academic productivity and that have been considered as “questionable”. However, there is no consensus about

\footnotetext{
aUniversidad Autónoma del Estado de Morelos, México (Autonomous University of Morelos, Mexico)

bDirección General de Educación Tecnológica Industrial-DGETI (Directorate-General of Industrial Technology Education), Mexico

\section{Correspondent Author:}

Ana Esther Escalante-Ferrer, Nueva Francia No. 124, Cuernavaca, Mor., C.P. 62245, Mexico

E-mail: anaescalante7@hotmail.com
} 
how unacceptable or not said conducts are, including: the criteria to determine authorship, the order of author listings, the deliberate inclusion or exclusion of authors and coauthors in academic texts, changing information or data, plagiarism, dishonesty, or negligence in relation with plagiarism, self-plagiarism, and "repetition"2 ("recycling" or "fixing"3 of contents), "piracy", of students, conflicts of interest due to affective reasons, corruption among peers, manipulation and student abuse or mistreatment expressed in some cases through the imposition of research topics in favor of a thesis director. These are some of the practices and behaviors through which professors reach rates and goals in order to gain positive evaluations for themselves and for the postgraduate studies they work for.

The authors of this work are convinced that evaluation is a process of continuous improvement, however, the particularities implied in different programs, institutions, professors, and evaluation systems may become polluted and may distort the purpose of the education process in postgraduate studies as well that of the production and diffusion of knowledge.

Taking this vision into consideration, the authors wonder: In what way do evaluation systems condition the practices and meanings of the professors' and students' behavior linked with academic productivity in postgraduate programs affiliated to the National Program of Quality Postgraduate Studies (PNPC) of the National Council of Science and Technology (CONACYT) in Mexico?

\section{BACKGROUND}

It seems that fraud in the investigation and observation of non-ethical conducts is increasing and in some places, it is starting to become a matter of concern and worry for scientific and academic communities. Nevertheless, it was interesting to find a lot of relapse in warnings about not grading and assessing as unethical conducts according to what we found in the texts that have been published about this topic in Spanish. We noticed that several of them are a product that is not related with premeditation, ill faith, predisposition, abuse, or planned fraud, but that sometimes may respond to a lack of information, experience, or (random) mistakes, or even to the use of an inadequate methodology.

In that sense, Eslava and Escobar (2012) edited a Colombian publication and mentioned what way fraud may include the intentional misunderstanding or manipulation of protocol, a situation that may put at risk the credibility of certain publications, their authors, the people who authorize their publication and their use in research and scientific work.

Both authors warn us about the fact that even if there is a base point from which a research work must be evaluated, mistakes in technical procedures can be caused by inexperience and even lack of preparation, and bad faith can lie behind the interpretation of random mistakes. To prove this, the authors can mention the 788 articles that were published in English between the years 2000-2010 and that were invalidated. Fifty-three percent of their authors had a record of having committed some kind of fraud in the past, while the articles that were mistakenly annulled mentioned as a first author a person who had shown a repetitive conduct in $18 \%$ of the cases. This is proof of a deliberate attitude that shows the intention of committing fraud (Eslava and Escobar 2012: 1).

For them, it is necessary to establish the difference among random mistakes, systematic mistakes (bias), and fraud. The last is the most concerning due to the intentionality it involves, and because it refers to a premeditated conduct that may include manufacturing, forging, plagiarism, or other unauthorized behaviors that are contrary to accepted practices, proposals, or results. One of the most easily identifiable of these practices is plagiarism, since there is a great variety of interpretations and delimitations of said conduct, depending on the field of study, the country, and the scientific culture that is involved. 
For this reason, they put aside random and systematic mistakes, because when they are not committed in bad faith, they are not considered as fraud. However, the three types of conduct have an impact on the quality of a scientific research and they cause a series of consequences that develop beyond the offender's will and time, because as authors say, quotes of articles that were annulled continued to appear for 24 years after their annulment. This shows the impact that any of these conducts may have.

On the other hand, Perellis, Palmero, and Roitman (2012) include in their work, the element of trust that society shows toward scientific activity, its participants, and scientists. Society assumes that the results and processes carried out by the people who are dedicated to this activity are the honest reflection of their education and commitment with their search for the truth. Scientists' contributions and even their opinions are usually assumed as correct, honest, truthful, and well-intentioned; characteristics that should be inherent in any researcher's education.

Yet, since 1980, and after the increasing discovery of cases in which exactly the opposite occurs, both in transcendent and in trivial situations, people are starting to show distrust and questions are raised: How is trust built and kept between a scientist and society? Can scientists be trusted?

To confront this situation, Perellis et al. (2012) developed the definition what they believe should be a Responsible Behavior in Research (CRI, in Spanish), which is understood as an honest scientific behavior that works in accordance with the parameters of precision in an efficient and objective way. This CRI goes beyond the limits of the researcher's personal behavior as it includes all the actors that are intrinsically participating in his work, namely institutions, sponsors, publishers, and even society. A researcher's integrity is being more scrutinized in scientific and academic policies and sometimes, in certain contexts, it is even a matter of concern for the state whenever resources have been assigned or depending on the outreach of the results of the scientific activity has on society.

For these authors, the areas that are at greater risk and that show the most relapse in this subject are: a conflict of interest, assignment of the corresponding credit/authorship, forgery and invention of data and, finally, plagiarism. Before this growing problem, Perellis et al. (2012) insist on concentrating on prevention, attention, and solving conflicts that emerge from all those cases in which the researcher's integrity is doubtful, whether or not the case has a judicial or economic transcendence, in order to protect scientific activity and its image.

Due to this, these authors conclude that there is a need to design efficient policies to promote the CRI that makes evident results obtained through scientific work. In other words, a researcher's integrity is not only his responsibility but also that of the institution he works for, the codes of conduct and rules that are established by his area of development to regulate and supervise the ethical aspects of the scientific process through the creation of committees and assessment councils.

And so, a researcher's work environment must be favorable but supervised to guarantee an ethical conduct. In that sense, these authors also mention the importance of not putting the researcher at risk of being corrupted and falling into unethical behaviors due to the pressure and competitiveness they confront. Finally, special attention must be given to the formation of new groups of researchers where there is an emphasis on guaranteeing their actions that are mediated by a culture of responsibility, honesty, and transparency, and the promotion of results, interchange of findings among researchers that belong to the same institution. In other words, the authors quote Lewis to summarize their proposal: "Integrity is doing the right thing even when nobody is watching” (Perellis et al. 2012: 54).

Regarding this same topic, Fanelli (2009) makes an analysis of "bad conducts" that take place in 
research processes and he mainly analyzes the manufacturing and forgery of results, which constitute scientific frauds that in terms of the medicine field, put human health at risk.

Fanelli declared that it is difficult to determine the amount of frauds or forgeries and that many times only researchers know that this information was manipulated. In their results, Fanelli reported that some scientists admit having fallen into these conducts and others have detected "questionable" practices and behaviors in their colleagues. The number of polltakers who admitted to having committed fraudulent practices ranges from $2 \%$ to $34 \%$.

Another article written by Fanelli (2010) talks about the problems that derive from the need to publish positive results that prove a hypothesis established by researchers from developing countries. This compromises the objectivity and integrity of research. The author considers that the publication of positive results is more accepted and quoted, so this promotes feeling biased to publishing this type of results.

In his studies, Fanelli learned that there is a connection between the pressure that is to publish and the errors in scientific literature. In order to verify this hypothesis, he used publications that dated from 2000 to 2007, and he declared that in a random sampling of 1,316 documents from all disciplines, the results could be significantly predicted from $25 \%$ to $100 \%$, because authors made the decision to publish works that adjusted to the findings made by prestigious academic work. Finally, he affirmed a matter that causes inevitable confusion in this study is the amount and prestige of academic institutions that are intrinsically bonded with their researchers' productivity.

Silva, Llanes, and Rodríguez (2007) point out the gradual increase in what they call inappropriate conducts in the production and communication of scientific results and research. They monitored Cuban scientific publications from 2004 to 2006, and they established a typology of incorrect forms of scientific activity by dividing them into two: severe and minor. The first refers to creating information, data forgery, plagiarism in all its forms, cyber or digital plagiarism, and even self-plagiarism.

As far as minor infringements, they included publishing repetitive, secondary, or parallel works, fictitious authorship, biased works, incorrect bibliographic references, and publicizing the results of a research. However, what they call a doubled publication-incorrect minor infringements colloquially known in Mexico as refrito, may be deemed as a "questionable" conduct since apart from the fact that in rigorous and transcendent academic events and in prestigious publications, they demand the presentation of original topics that have not yet been exposed and/or published, sometimes they offer "variations of one same work" arguing that they have updated the information regarding the object of study.

For Silva et al. (2007), it is necessary to demystify the scientists' behavior, assuming that their work is not exempt from passions, acts of corruptions or malpractice, since they are part of and a result of the society they develop in and they are exposed to different needs such as: interests, prejudice, ambition, need of recognition, desire of self-promotion, and income.

These inadequate or incorrect conducts must be fought against because of the ethical implications that they represent in science, so they recommend preventing them in order to further advance in their eradication and in the interiorizing of codes among new researchers. This might be a good alternative to stop and reduce said conducts.

It is important to say that just like other revised works, these authors speak of the need to avoid labeling as inappropriate conducts those are determined by ignorance or error and not by will or bad faith. For this reason, they recommend taking into account what they call honest mistakes. Yet, these elements make it more difficult to determine if it is 
necessary to proceed or not against an inappropriate conduct.

In Mexico, in educational pre-graduate and post-graduate programs, it is not frequent to analyze in detail, together with the students, the problems associated with "questionable" practices and behaviors by teachers and researchers who, by the way, are not completely except of having incurred in said conducts. Perhaps we should reconsider Silva et al.'s proposal (2007) and systematically get students and researchers to analyze, comment, and reflect on academic plagiarism as well as on other conducts that somehow violate the transparency and honesty of scientific work.

During a research project about professional ethics, Hirsch published a work about non-ethical conducts in a university atmosphere in a Mexican journal in 2012, particularly in relation with the use and self-benefit of published works. The author warns us about the importance of analyzing and correcting this problem due to the negative implications it provokes in institutions and scientists.

The first problem that is related with non-ethical conducts, is determining the authorship of a literary scientific product. How can we determine who is the first author of an academic product? There are many ways to solve this situation, and in some cases, they can invite students and/or teachers to commit plagiarism or at least fall into an unethical conduct.

Particularly, Morillo (2001), speaking about health in Colombia, talks about the existence of three criteria to determine a work's authorship. The first author must be the person who has substantially contributed to: planning and designing the study or the analysis, interpretation of data, elaborating the article's first draft or its critical analysis with important contributions in content, and approving the final version that is to be published. At the same time, several editorials demand that for every article that is to be published, its creators mention the specific role each author had in its creation.
Still, according to Morillo (2001), despite some advances, there are still cases that cause suspicion and even serious problems regarding a scientific work's authorship, specially when a text is worthy of a prize or academic acknowledgement, vice versa, whenever it is questioned or accused of fraud. Morillo (2001: 4) affirms that: "Among the reported problems, the most common is unsatisfied potential authors who believe that they have not been granted a well-deserved recognition, or that they find that some of their co-authors should not be included in the final authors list”.

For Morillo (2001: 4), the problem of authorship must be confronted with formality and following certain ethic norms instead of giving away acknowledgements, courtesies, or misunderstood solidarities, to say the least, because it is also known that some people "include others in their work if it is reciprocal”.

There are no universal norms to regulate this situation. Before this void, at least certain previous agreements may be established before writing the product or academic work, based on criteria that are as objective as possible. In certain fields of knowledge and in certain countries, journals or publications establish the requirements that every author or coauthor must meet, or even the ones they need to thank or acknowledge someone's work.

The most common regulation to avoid authorship conflicts is planning a considerable participation from all collaborators from the beginning of the project. If everyone acquires the same commitment in the development of the different phases of a certain work and all the potential researchers participate in different activities related with a project, it is very probable that in the end, there will be no significant differences in the perception of the relevance of each author's work.

From the beginning, it must be established who will be the authors of the product and the order in which they will be listed according to the responsibilities they have in the production of the 
work. This must be determined before elaborating the protocol. A project's authors must agree on the final version of the work as well as on the decision of publication to which they will present the product (Morillo 2001).

Morillo (2001) believes that in order to avoid the proliferation of practices and behaviors qualified in this work as "questionable", the first step is to promote an intense diffusion of the accepted norms established in a country, according to the corresponding scientific branch, among academic groups in formation and well-established researchers. Again, educational institutions seem to be the best route to eradicate said conducts and practices.

Yet, in other fields of knowledge, according to Acosta (2007), the lack of a definition that establishes with certainty of the authorship of a work and the order of coauthorship of academic articles, there might be a problem that leads to other situations that without necessarily resulting in plagiarism may favor the existence of unethical actions.

Even though it is true that in many institutions, there are no objective and regulated criteria to establish the authorship and coauthorship of those who sign an academic product, they subjectively value the order in which the authors of a publication are listed. There are education institutions as well as research centers with diverse criteria to determine which author should go first. In some occasions, the definition depends on prestige or political or academic convenience, pressure from external sources, productivity or academic status. Further yet, sometimes researchers accept or allow to be named as authors or co-authors of productions in which they do not have a direct participation. This subjectivity relies on the fact that while in a certain country and area, it is common for an academic product to include six or even more co-authors, there are other places and disciplines in which the inclusion of so many authors demerits the work.

In the Mexican context, being listed as an author represents certain benefits that are translated into work advantages, academic status, and/or extra points for economical stimulus systems. And the order in which the authors are listed is frequently taken into account by assessing organisms or institutions. This even happens when students write their thesis appear as co-authors together with their director or their tutoring committee $^{5}$. According to Acosta (2007), the author of a work is defined as the person who writes a literary work, creates it or gives birth to it. For the American Psychological Association (APA), an author is that who makes substantial scientific contributions to a research, participates in the problem and formulation of the experimental design, and writes the greatest part of the article or research report.

On the other hand, Acosta (2007) consider that an author is that who makes a substantial contribution to a research and the text that results from it, but once again, there are elements of subjectivity. How much is substantial? How can you measure it? How can you identify in a concrete and certain way how much each of the authors or coauthors participated in the work?

In sum, determining who should appear as author and who should be the co-author(s) is affected by several matters which, in some occasions, provoking ethical problems. In that sense, Acosta (2007) offers an interesting proposal with objective ideas that may establish, from the beginning of the work, each participant's contribution and the order of author listing that will appear in it, avoiding with this conflicts and awkward situations.

Parting from the case study that De la Lama (2011) made through an exploratory poll, our opinions as scientists who are affiliated to a Mexican public university and acknowledge (88\%) the existence of informal regulations in scientific research, only $9 \%$ were able to identify them. The author specified that having methodological abilities is a necessary resource for the development of scientific activity by any academic, although that is not enough when said academic is exposed to institutional demands and 
competition for economic stimuli and academic recognition. This may lead to inadequate conducts like fraud, plagiarism, and lack of scientific rigor, all qualified as undesirable practices even if they are common in the work done by researchers.

Regarding the question: Which are the undesirable practices carried out by specialists? De la Lama (2011) replies that in general they are: mimicking, theft, and copying information. For this reason, he proposes that the scientific community acknowledges the establishment of at least one rule that will determine the difference between a true scientist and a wannabe: A critic attitude through which the researcher will adopt the responsibility of applying universal values to all the processes that are related with his work.

In other words, a permanent critic attitude toward his own knowledge that allows a hypothesis to be empirically proved wrong, added to availability and commitment toward showing in a public, clear, precise, and order way the methods and reasoning that led him to prove the validity of his ideas. Also, accepting being confronted with a critical analysis carried out by his peers. Following this rule should be mandatory and applicable to every area of study.

Permanent commitment with one's work is, together with ethical behavior, the basis for every professional to fulfill-in a personal and collective way-his responsibility within the social group he belongs to. For Araujo, Clemenza, and Ferrer (2006), researchers just like any other professional are not exempt from abiding by an ethical desired and expected behavior. In order to confront ethical dilemmas that their career continuously demands, they require a reflective and critic capacity, anchored in ethical values, but that goes beyond knowledge and written policies.

For these authors, a researcher's attitude must be guided by the consistency of the transcendence, his professional work will have in the context he lives in. For this reason, promoting and practicing democratic values in one's professional career promotes the construction of a society based on freedom, equality, tolerance, solidarity, mutual respect, performance of duties, and granting of rights.

The ethical dilemmas that according to Araujo et al. (2006), a scientist needs to confront, force him to act according to a series of ethical and moral values, among which we can name: Using only legal means to gather information, judging critically when selecting the techniques that will be used in a certain work, protecting the rights and identity of the individuals that are involved in doing research by preserving their confidentiality if needed, treating interviewees with respect, guaranteeing the information that was gathered is not altered for any reason and assessing facts objectively. In that sense, they establish that:

A researcher faces multiple aspects that may act against ethical and moral principles: even paraphrasing ideas without quoting an author or partially or completely copying a text; disregarding the norms of presentation of an article and even reproducing articles (Araujo et al. 2006: 178).

Definitively, according to these authors, it is not enough to write and promote regulating norms that are learned by students and researchers in formation, it is necessary to have a "broader ethic understanding of the implications and effects that said professional's behavior has over all the contexts and areas that are affected by his actions" (Araujo et al. 2006: 178). This involves an educating process in the broadest sense of the word that revitalizes and reinforces basic ethic characteristics for their education and career.

\section{METHODOLOGY DESCRIPTION}

This research was developed with a qualitative scope, the interpretative tradition that lies under the data analysis is an approximation to what was mentioned by Gallagher (1999) as hermeneutic and conservative since we assume that the text derived from the accumulation of facts, through both analyzing post graduate professors' productivity and transcribing 
interviews, reflects the author's intentions. Apart from that, it is possible to solve some kind of discrepancies between the interpreter and the text based on rational principles.

This research was carried out in two stages, the first one allowed us to determine the high level of productivity that was achieved by the professors of two postgraduate programs in a public university. By using numerical data (number of products per professor in a determined time lapse), the authors made their research in internet and in a library to learn about the academic unit of these programs and they found 36 texts that were co-authored by colleagues and professors-students. The authors elaborated an analysis and pointed out the publications that seemed to derive from one same research.

Later, in the second stage, they did the same within a research project about work forms and ethics in Academic Groups ${ }^{6}$. For this paper, they took the testimonies given by nine of 18 interviewees that included researchers-professors of two Mexican states public universities who participated in six postgraduate programs related with social sciences and human studies that belonged to the PNPC and in which the interviewed professors act as master and/or $\mathrm{PhD}$ thesis directors. Throughout the interviews, the authors talked to them about the ethical and non-ethical practices and behaviors that occur in their institutions. The theoretical framework that allows them to complete the hermeneutical cycle reflects the conceptual ambiguity of behaviors that occur and respond, in some cases, to assessment processes that both institutions and subjects need to fulfill in order to obtain financing and scholarships.

\section{RESULTS}

Without ceasing to acknowledge that in some cases, co-authorship means a collective effort that reflects the importance of teamwork, other times it reflects non-ethical practices like including colleagues-who are part of constituted groups of research, and/or students as co-authors without them having necessarily done any teamwork or collaborated in doing the research that is published, all with the purpose of improving and/or maintaining the evaluation level that was already achieved by a certain Academic Group.

The authors speculate that the evaluation demands of academic processes throughout the last 15 years have led to "questionable" practices and behaviors that are difficult to determine, among which they find all that is implied in co-authorships of academic products. As a consequence of this reflection, this article shows the result of the assessment of documents that were produced and the analysis of several interviews regarding practices and behaviors for the publication of academics as well as meeting deadlines for postgraduate thesis in six programs of two public universities.

Derived from the analysis made to the academic productivity reported by the PNPC of two of the six programs that are analyzed in this work and the diverse types of publications (author books, coordinating projects and editing books, translated books and collections, articles in indexed and revised publications, book chapters and reviews) of a group of professors that includes $18 \mathrm{PhDs}$, the authors found that the professors of said program have made use of all possible means to make their research visible. Together, in a period of five years (2008-2013), they published 34 books, 94 articles that were revised in national publications, 52 in international publications, 145 chapters in national books, 27 in international books, and eight reviews: in total, 365 diverse publications. Some of these products were co-authored with colleagues and/or students that they guided throughout the programs that belonged to their corresponding academic unit, while others were co-authored with students from other programs.

The production volume that was reported allows us to confirm that, in sum, the group of professors 
published one book every two months, over two chapters in national books every month, one book chapter in an international book every two months, three bimonthly articles in national publications, almost one monthly article in international publications, and one review every eight months. Every month, they published average six research products of diverse topics; this announces a monthly productivity per capita of .33 in a period of five years. This indicator offers an example of productivity of the members of a basic academic group in two of the postgraduate programs they studied ${ }^{7}$.

These results raised doubts, so the authors wanted to analyze in detail the type of publications and coincidences between the subjects that were published in co-authorship by comparing them with the research that is made or developed by these same professors and by the students of the program. One of the goals was to analyze authorship and the order of co-authorship with the purpose of determining unethical behaviors and the elements associated with these practices.

Among them, we could find the pressure caused by evaluation models in which the professors, students, and institutions participate in order to stay in the PNPC. They may also be caused by the existence of indexed journals that do not allow students to be listed as a first co-author when he publishes together with his thesis director. This might not depend on the director's ethics. And yet, another possibility is when a student prefers his professor to be listed first, because he is not known in the academic world but wants to profit from the impact his professor's name might have. Situations like these complicate determining to what extent these practices and behaviors are "questionable".

Of the 36 products the authors analyzed, 30 correspond to works written in co-authorship between students and professors of the program and six by professors with students from other programs. These academic products, depending on their type, are distributed in the following way: 17 book chapters, seven lectures and six articles for journals; the products elaborated by professors together with students from other programs are equivalent to three book chapters and three lectures.

In co-authorships between professors of the programs they studied and students from these programs, the authors found the following:

(1) One case in which two professors that belong to an Academic Group published a work together with students who were under their guidance. This responds to recommendations and/or requirements by assessment organizations related with the formation of human resources;

(2) The authors detected cases in which a professor and researcher was responsible for a research project that served as a source for the thesis of a student under his guidance and that it was the professor who was listed as the publication's first author. On one hand, they could consider it a "questionable" conduct from the academic's point of view, because the work shows advances in his student's research. However, there is also the possibility that the link of said thesis work with the academic's research project determines this situation. Even more, the student is the one who suggested co-authorship, a situation is also questionable;

(3) Despite the fact that the work may be about the student's thesis, the director appears as the first author of the text in only $16 \%$ of the cases they studied. However, this could be seen as an abusive of students, although it is possible that they prefer the authorship to be granted to their director for matters of prestige;

(4) They found cases in which a student appeared as a co-author in a work that corresponded to a professor's topic and that said professor was not his thesis director while the thesis director was not listed among the authors. This may be related with a situation that was exposed by the interviewed professors of the programs and that corresponds with what they call "piracy" of students; 
(5) We also found a case in which a thesis director developed a theme that greatly differed from that of his student's and yet, the student was listed as the first author in the professor's line of research. This suggests an intention of favoring the student;

(6) Thirteen percent of the works published or presented did not correspond with the first listed student's thesis topic, but with that of another student was part of the program. This means that the one responsible for this research was listed second and even third. This may be seen as abuse or as an intention to favor another student;

(7) Among the works produced in the programs, only in half of them they found that the first author was that who developed projects in a certain line of research of a topic. These cases may respond to the need of getting economical support, maintaining an adequate academic level for the program or responding to the system's demands of constant and abundant production, affecting the interests of colleagues and/or students, or even the possibility of sacrificing the individual in favor of a group.

In co-authored works by a program's professors and other program students, the authors found that:

(1) One-third (five times more than in the previous section) of professors were listed first in their research projects. This is evidence of the respect shown to the professor's knowledge about a research topic and how it is reflected on the publication's authorship;

(2) Proportionally, in relation with the studied cases, authorship in student's thesis project shows more evidences of the professor being listed first in $33 \%$ of cases, perhaps for prestige reasons;

(3) Finally, we found that same percentage (33\%) in professors who allow other programs' students to be listed first in publications that correspond with the topics that the professor develops.

In the second stage of this research work, the authors agreed with Aluja and Birke (2004: 113). Among "questionable" conducts, they include those which are related with "conflicts of interest" understood as "all those actions or behaviors through which a personal benefit is gained in an abusive way, whether with the purpose of obtaining a better work situation or for a personal economical benefit” directly or indirectly. In that sense, professors-researchers pointed out that:

If (there comes a time when) telling (a student) that we've waited for a long time and it's (...) time to finish, then I'll write the article. Why not? It's all right, (...) it has not caused any conflict but no, he won't be listed as an author. It's my name who appears as that of the author's... (F:L: $2014)^{8}$

(...) everyone knew that he "directed" a student's thesis who was actually his/her partner. (F:A: 2014)

Silva et al. (2007) talk about inadequate conducts including plagiarism in publications. In that sense, the authors mention self-plagiarism, doubled-publications, parallel publications, and fictitious publications. The interviewed professors exemplified those situations by saying that:

(Students) are tempted to do collective work, or to add touches to something that had already been done before. (F:C: 2014)

There's plagiarism and in many cases, there's lack of honesty in the presentation of information, so there is a use of incorrect data and the intention of making the least effort. (F:P: 2014)

Plagiarism is (common). We struggle with the students and that is evident for all of us. It's unacceptable that a student simply copies a paragraph without quoting the source. (F:F: 2014)

We were told in interviews that they also notice how teachers carry out unethical conducts when they want to produce more. (F:A: 2014)

Amador and her collaborators (Amador, Brás, and Galleros 2012) assure that some of these conducts are due to the pressure to which professors are summited so that their works are published. However, the action of deciding imposingly to whom a work's authorship should be granted, has not been qualified with a specific term. Such is the example of a student who 
appears in a publication as the first author of a product that is not related with his thesis topic but with that of another student.

The aforementioned authors quote from Bacallao, Barber, and Roca (2003), the two different causes of inappropriate conduct: exogenous and endogenous. The first is independent from the researcher and associated with social and institutional pressure regarding productivity, personal, or corporate competency and inefficient control of scientific activity. The latter is related with a researcher's personal qualities that include a lack of ethical values. Throughout the interviews, the authors found out that:

Some students (that) have not done what is asked of them and (trust) that their director will speak with others so that their work is accepted (...) even though the work was not sufficiently developed. (F:A: 2014)

They steal thesis from writers and convince them that their thesis director is not doing his/her job well enough and that they should ask for a reassignment. (F:A: 2014)

So I worked through most of the process together with a certain student and someone else comes and steals him. (F:C: 2014)

(...) the conflicts started, the corrupt agreements that had been made emerged. (F:A: 2014)

On the other hand, when the authors reflect on the sense of questionable practices and behaviors, and they take into account the contribution by Domínguez and Macías-Ordóñez (2004), in a poll that was made to 146 academics, they detected conducts in which professors: mistreat students, abuse their power, sexually harassed students, manipulated authorship (researchers appear as authors of articles they did not work in or only had a limited participation), complicity (researchers are witnesses of situations of lack of ethics and do nothing to avoid it, denounce it, make it right if possible and sanction it), lack of commitment (researchers obtain the benefits of belonging to an academic institution but do not pay back with their work), unfair evaluations, fraud (fraudulent use of information to favor a hypothesis or increase the rate of publication), "points-are-all" (researchers worry more about countable production of products associated with individual evaluation systems), plagiarism, lack of formality and sabotage (researchers intentionally impede the scientific advance of their colleagues). Some of these conducts are exemplified in the following situations:

Sometimes, students say that their thesis directors don't read their work, or insult them, undermine their work or degrade them. (F:A: 2014)

I believe that sometimes people who know a lot or who think they know a lot no longer have their feet on the ground ${ }^{9}$, and in that sense I have considered fighting for the students. (F:C: 2014)

I think it's totally unethical to ask a series of students to gather information for me to do my own research or my own publication in which they're not included. (F:C: 2014)

Silva et al. (2007), Aluja and Birke (2004), and Domínguez and Macías-Ordóñez (2004) consider that in order to correct these practices, we can demand that there are individual and institutional permanent self-evaluation mechanisms that promote the creation of an institutional ethics code that serves as a reference for all the members of a community. Some of the current evaluation mechanisms sometimes taint the activities that are carried out in terms of publications with the purpose of meeting expected requisites and obtaining "excellent" results in evaluations.

For this reason, the authors of this work disagree with the predominating demand for excellence and adhere to the sense of excellence that Latapí (2007: 213) proposed.

The purpose of being excellent harbors a trap of secret arrogance. We can and must become better, but not perfect. What a healthy pedagogy must pursue is to invite us to develop our talents, worrying about how they will serve others.

Before the demands of abiding by requirements of quality in accordance with the current evaluation models, both educational programs and stimuli for 
professors and researchers, we will have to analyze mechanisms that say they search for "excellence" when they actually demerit its achievements. Such is the case of practices like these:

Another thing is that professors write a thesis for their students. One thing is to work with them but not for them. You can suggest a methodology but not force them to follow your line of research. (F:A: 2014)

Evaluations and institutions are forcing us to fall into not very honest attitudes. (F:C: 2014)

It is convenient to acknowledge that there are also ethic conducts that promote the education of high-level human resources that create knowledge. Here are some testimonies that serve as proof:

So we met and analyzed educational public politics and we discussed several topics. I had just directed a thesis work about the topic of change and transformations in public organizations in terms of higher education. (M:P: 2014)

That was our first product. We started to produce books as co-authors and that was helpful for them. They liked it because part of the PROMEP policy (is) to promote teamwork and do things together. We did our homework and were consolidated a year ago. (M:P: 2014)

$\mathrm{No}$, in response to public policy, you have to educate people who publish with you, that is not something we have as a goal. We have to include them in these practices that are common for us. (M:P: 2014)

Yes, we invite them to publish with us. (M:L: 2104)

But above all, in joint publications, we talk about the concepts we use. I work with them so that they understand that teamwork (is) participating in writing, revising, and assessment. (F:A: 2014)

Sometimes, a publication written with a student who has (participated) permanently in the seminar is merely a collaboration. (F:F: 2014)

Sometimes, there's a real collaboration and sometimes it's a cooperation. (F:F: 2014)

Finally, we can notice that evaluation policies for programs and professors have created changes in their practices and those of their postgraduate students. And sometimes, they have derived in unethical practices while in other cases, they have positively transformed the process of formation of new researchers.

\section{CONCLUSIONS}

This paper is part of a work in which the authors have analyzed different aspects related with the production of knowledge in postgraduate programs. However, they are sure that the presentation of these shows self-criticism and the capacity to respect the rights of others and prevent abuse. One of the results of this review could be to publish a work regarding copyright, giving the corresponding credit to each participant and acknowledging only those people who actually participate.

Based on the findings, the authors propose a typology of the conditions in which they observe the establishment of authorship in the production of the postgraduate programs they studied, within the context of current evaluations:

(1) Coherent authorship: The first author has had a consistent production. This shows that the published work strictly corresponds with what he/she has done research about; the lines of research, in the case of professors, and a topic that is related with his/her postgraduate research, in the case of students;

(2) Fictitious authorship: In which the first author is not who has developed a topic or line of research (Amador et al. 2012). It includes cases of favoritism for some student, giving him/her the opportunity to appear as author when he/she is not writing about his/her thesis topic; or even naming someone as first author of the work of another student;

(3) Inadequate authorship: It is when the first author is not strictly that who should be named first. In these cases, they include those works in which students are exploited, but also those in which a student or professor is benefited without deserving it.

This paper also provides interesting evidence of what we have called "questionable" practices and behaviors in which we identify the opinion, point of view and situations that are not written in documents but are talked about in institutions. Among "questionable" practices and behaviors that other 
authors call inappropriate or incorrect, the authors find repetition or refrito, as we call it in Mexico. The quoted authors call it doubled or redundant. This situation, when analyzed in empirical work, seems to be caused by both personal and institutional interests, particularly economical, promoted by wanting to gain recognition or meet quality requirements that are used to evaluate researchers and postgraduate programs.

One practice that was not fully explained in these testimonies is related with the decision of the order in which authorship of academic products is listed, whether because that work is a result of different research works elaborated by a group, or because the information has been gathered by students while the professors submit the text for publication. This practice is frequently mentioned in other publications and several proposals have been given to keep it from happening. For example, they have mentioned creating previous agreements about the order of authorship listings before the research work is executed.

The intervention of evaluation policies is not useful when collaboration works in which activities are fairly distributed, the first author receives greater recognition than the rest of the team members, as it should be if there was not an evident ruthless struggle to gain more points.

Finally, the authors consider that the evaluation methods and mechanisms need to be revised, since the practices and behaviors that have resulted in some cases are a fraud. They meet requirements but there is no improvement in the quality of processes. They do not reflect the work and the achievements of the students, the professors, and programs. The student is no longer the end of the educational process and becomes the means for institutions and professors to gain acknowledgement and resources in a process of education merchandising.

\section{Notes}

1. Autonomous University of Mexico, Autonomous University of Baja California, Autonomous University of Nuevo León,
University of Monterrey, Autonomous University of Sinaloa, Autonomous University of Tamaulipas, Autonomous University of Morelos, University of Guanajuato, Iberoamericana University-Puebla, Michoacán University of San Nicolás de Hidalgo, Autnomous Juárez University of Tabasco, Veracruz University, Autonomous University of Chiapas, Autonomous University of Yucatán, Autonomous University of Zacatecas, Universidad de Colima, Autonomous University of Campeche, and Autonomous University of Tlaxcala.

2. In the academic world in Mexico, we colloquially call refrito any work that is a presentation and/or publication of an academic product with slight variations that make it seem original.

3. The term "recycling" or "fixing" refers to using a text that had already been presented in another place or time.

4. By "piracy", we mean the action of stealing a thesis, writer from a professor who had been formally assigned to him through proposals (scholarships, coauthorship in publications, mobility support with the intention of taking benefit from the work that the professor had already made and the student's potential).

5. In Mexico, in some postgraduate programs, the student is assigned a thesis director from the beginning of the program as well as two other professors that conform the tutorial committee that reads, checks, and evaluates the student's advance in his/her research.

6. It is a group of professors-researchers who share one or more lines of research, whose golas and objectives are destined to the generation and/or application of new knowledge. Besides, due to the great level of specialization that they reach together when teching, they achieve a good education quality. Academic Groups are the base of institutional academic functions and they contribute to the integration of the higher education system of this country. Retrieved (http://dsa.sep.gob.mx/cuerposacademicos.html).

7. This information was analyzed by a group of professors from both programs for the process of evaluation with the purpose of remaining in the PNPC.

8. To protect the confidentiality of respondents, scores $\mathrm{X}: \mathrm{X}$ : XXXX means the first initial corresponds to the sex of the individual, the second letter refers to the initial of the the first name, and the four digits are the year the interview was conducted.

9. We use this phrase to make reference to an arrogant attitude that does not take into consideration the possibility of taking the rightful place in the education process.

\section{References}

Acosta, A. 2007. "How to Define the Authorship and Order of 
Authorship in Scientific Papers Using Quantitative Criteria.” Journal of the Faculty of Science, Universitas Scietiarum. Retrieved (http://revistas.javeriana.edu.co/index.php/ scientarium/article/viewFile/4862/3742).

Aluja, M. and A. Birke. 2004. "Panorama general sobre los principios éticos aplicables a la investigación científica y la educación superior" (Overview of the Ethical Principles for Scientific Research and Higher Education). Pp. 87-143 in El papel de la ética en la investigación científica y la educación superior (The Role of Ethics in Scientific Research and Higher Education), edited by M. Aluja and A. Birke. 2nd ed. Mexico: Fondo de Cultura Económica \& Academia Mexicana de Ciencias.

Amador, R., I. Brás, and L. Galleros. 2012. "Plagio académico y ética profesional en las universidades” (Plagiarism Academic and Ethical Professional in Universities). Pp. 297-320 in Ética profesional en la docencia y en la investigación (Professional Ethics in Teaching and Research), edited by A. Hirsch and R. López-Zavala. Mexico: Universidad Autónoma de Sinaloa, Universidad Autónoma de Baja California, Universidad Autónoma de Tamaulipas, Universidad Michoacana de San Nicolás de Hidalgo, Universidad Popular Autónoma de Puebla \& Editorial De Lirio.

Araujo, R., C. Clemenza, and J. Ferrer. 2006. "La formación del investigador latinoamericano" (Education of the Latin American Researcher). Multiciencias 6(2):174-179. Retrieved (http://www.redalyc.org/articulo.oa?id=9046 0211).

CONACYT (The National Council of Science and Technology). 2013. Convocatoria 2013-1: Programas que renuevan vigencia al National Census of Quality Postgraduate Studies (Announcement for 2013-1: Programs Which They Renew Effect at National Census of Quality Postgraduate Studies). Retrieved (http://siicyt.main.conacyt.mx: 9098/psp/REGCYT/EMPLOYEE/REGCYT/s/WEBLIB_P T_NAV.ISCRIPT1.FieldFormula.IScript_PT_NAV_INFR AME?Folder=FORTALECIMIENTO_POSG\&CREF=\&Fo lderRef=FORTALECIMIENTO_POSG\&c=uSXnnFSrvtN Xzjzg35npD9TPSr5x8ajdlL7R2oaTL9HZbR66PfPoVZTG HYMkwtsu).

De la Lama, A. 2011. "Existen reglas implícitas dentro de la investigación científicas?” (There Are Implied Rules Within the Scientific Research?). Revista de la Educación Superior 4(160):74-98. Retrieved (http://www.redalyc.org/ articulo.oa?id=60422569004).

Domínguez, C. and R. Macías-Ordóñez. 2004. "El que no tranza no avanza: La ciencia mexicana en el espejo" (Which not Swindle Does not Advance: The Mexican Science in the Mirror). Pp. 87-143 in El papel de la ética en la investigación científica y la educación superior (The
Role of Ethics in Scientific Research and Higher Education), edited by M. Aluja and A. Birke. 2nd ed. Mexico: Fondo de Cultura Económica \& Academia Mexicana de Ciencias.

Eslava, J. and F. Escobar. 2012. Error aleatorio, sesgo y fraude en las publicaciones científicas (Random Error, Bias and Fraud in Scientific Publications). Retrieved (http://www. revcolanest.com.co).

Fanelli, D. 2009. "How Many Scientists Fabricate and Falsify Research? A Systematic Review and Meta-analysis of Survey Data.” PLoS One 4(5):e5738.

_ 2010. "Do Pressures to Publish Increase Scientists' Bias? An Empirical Support From US States Data.” PLoS One 5(4):e10271.

Gallagher, S. 1999. Director: Honors Seminar on Hermeneutics at Canisius College. Retrieved (http://www.canisius.edu/ gallaghr/ah.htlm).

Hirsch, A. 2012. "Conductas no éticas en el ámbito universitario" (Unethical Behavior at the University Level). Revista Perfiles Educativos 34(Special Number).

Latapí, P. 2007. “Conferencia Magistral al recibir el Doctorado Honoris Causa de la Universidad Autónoma Metropolitana de México” (Keynote Address to Receive the PhD Honoris Cause From the Universidad Autónoma de Mexico). Revista Iberoamericana sobre Calidad, Eficacia y Cambio en Educación 5(3):210-218.

Morillo, A. 2001. Conceptos sobre autoría, en Revista Colombiana de Radiología (Concepts of Authorship). Retrieved (http://www.medtrad.org/escaparate/Anibal JMorillo.htm).

Parellis, L., A. Palmero, and A. Roitman. 2012. "Conductas Responsables en Investigación. Definiciones y aplicaciones” (Responsible Behavior in Research. Definitions and Applications). Revista Redbioética/UNESCO 1(5):43-54. Retrieved (http://www.unesco.org.uy/shs/fileadmin/shs/ redbioetica/Revista_5/Perelis4354R5.pdf).

Silva, D., R. Llanes, and A. Rodríguez. 2007. "Manifestaciones impropias en la publicación científica” (Unfit in Scientific Publishing Events). Revista Cubana de Salud Pública. Retrieved (http://www.redalyc.org/articulo.oa?id=21433 409).

\section{Bios}

Ana Esther Escalante-Ferrer, Ph.D., professor, Instituto de Ciencias de la Educación (Education Sciences Institute), Universidad Autónoma del Estado de Morelos (Autonomous University of Morelos); research fields: educational devices, knowledge in education and training, ethics, policy and diversity in organizations and in processes of actors in 
education with geneder perspective.

Luz Marina Ibarra Uribe, Ph.D., professor, Facultad de Estudios Superiores de Cuautla, Universidad Autónoma del Estado de Morelos (Autonomous University of Morelos); research fields: ethics, policy, and diversity in education.
César Darío Fonseca Bautista, Ph.D., professor, Dirección General de Educación Tecnológica industrial-DGETI (Directorate-General of Industrial Technology Education); research fields: ethics, policy, and diversity in education. 